\title{
Çalışanlarda Akış Deneyimi Oluşturulması: İş Biliş Envanteri ve İçsel Statünün Önemi Açısından Bir İnceleme \\ (Generating Flow Experience in Employees: A Study on the Importance of Work Cognition Inventory and Insider Status)
}

\author{
Büşra MÜCELDİLI iD a Berivan TATAR iD b Oya ERDİL iD \\ a Gebze Teknik Üniversitesi, İşletme Fakültesi, Kocaeli, Türkiye. bmuceldili@gtu.edu.tr \\ b Gebze Teknik Üniversitesi, İşletme Fakültesi, Kocaeli, Türkiye. btatar@gtu.edu.tr \\ cGebze Teknik Üniversitesi, İşletme Fakültesi, Kocaeli, Türkiye. erdil@gtu.edu.tr
}

\begin{tabular}{|c|c|}
\hline MAKALE BİLGİSİ & ÖZET \\
\hline Anahtar Kelimeler: & Amaç - İş akış deneyimi kavramı, çalışanların tutum ve davranışları üzerinde olumlu etkiler \\
\hline $\begin{array}{l}\text { İş biliş envanteri } \\
\text { İş akış deneyimi } \\
\text { içsel statü }\end{array}$ & $\begin{array}{l}\text { yaratması sebebiyle son yıllarda örgütsel davranış ve yönetim alanındaki araştırmacıların ilgisini } \\
\text { çekmiştir. Buna rağmen kurumların çalışanlarda akış deneyimini nasıl yaratacağına dair bilgi ve } \\
\text { bulguların sınırlı kaldığı görülmektedir. Bu bağlamda bu çalışmanın amacı, çalışanların örgütsel, iş } \\
\text { ve kişiler arası deneyimine ilişkin boyutlardan oluşan İ̧̧ Biliş Envanterini incelemektir. Bunun yanı }\end{array}$ \\
\hline $\begin{array}{l}\text { Gönderilme Tarihi } 17 \text { Ağustos } \\
2019\end{array}$ & $\begin{array}{l}\text { sıra İş Biliş Envanteri içerisindeki deneyim unsurları, içsel statü ve iş akış deneyimi arasındaki } \\
\text { ilişkileri incelemek amaçlanmaktadır. }\end{array}$ \\
\hline $\begin{array}{l}\text { Revizyon Tarihi } 16 \text { Kasım } 2019 \\
\text { Kabul Tarihi } 2 \text { Aralık } 2019\end{array}$ & $\begin{array}{l}\text { Yöntem - Araştırma kapsamında anket yöntemiyle farklı sektörlerde çalışan } 200 \text { katılımcıdan veri } \\
\text { elde edilmiştir. Elde edilen verilerin analiz edilmesinde faktör analizi, güvenilirlik ve geçerlilik } \\
\text { analizi kullanılmış ve araştırma hipotezlerinin test edilmesinde yapısal eşitlik modellemesinden } \\
\text { faydalanılmıştır. }\end{array}$ \\
\hline \multirow[t]{2}{*}{$\begin{array}{l}\text { Makale Kategorisi: } \\
\text { Araştırma Makalesi }\end{array}$} & $\begin{array}{l}\text { Bulgular - Araştırma sonuçları iş biliş̧ envanterinin, iş akış deneyimi ve içsellik statüsü üzerinde } \\
\text { pozitif etkisinin olduğunu, içsellik statüsü algısının ise iş akış deneyimi üzerinde bir etkisinin } \\
\text { olmadığını göstermiştir. }\end{array}$ \\
\hline & $\begin{array}{l}\text { Tartışma - Araştırmanın bulguları doğrultusunda, kurumların çalışanlara sundukları çalışma } \\
\text { ortamının farklılaştırılması ve eşsiz bir deneyim sunulmasının kurumlar açısından avantaj } \\
\text { sağlayacağ görülmüştür. Buna ek olarak örgütsel, kişiler arası ve iş deneyiminin bütüncül olarak } \\
\text { değerlendirilmesi, çalışanların içsel statülerini ve akış deneyimlerini olumlu etkileyecektir. }\end{array}$ \\
\hline
\end{tabular}

\begin{tabular}{|c|c|}
\hline ARTICLE INFO & ABSTRACT \\
\hline $\begin{array}{l}\text { Keywords: } \\
\text { Work cognition inventory } \\
\text { Work-related flow } \\
\text { Insider status }\end{array}$ & $\begin{array}{l}\text { Purpose - The concept of work-related flow has taken great attention of scholars in the } \\
\text { organizational behavior and management field because of creating a positive impact on the } \\
\text { employees' attitudes and behaviors. However, knowledge and finding about how organizations } \\
\text { create the flow experience in employees' point of view has been scarce in the literature. In this } \\
\text { context, the aim of this study is to examine the Work Cognition Inventory which consists of the } \\
\text { organizational, job and interpersonal experience. Additionally, it has been aimed to investigate the } \\
\text { relationship among different experience aspects of Work Cognition Inventory, perceived insider } \\
\text { status and work-related flow experience. }\end{array}$ \\
\hline \multirow[t]{3}{*}{$\begin{array}{l}\text { Article Classification: } \\
\text { Research Article }\end{array}$} & $\begin{array}{l}\text { Design/methodology/approach - Data were obtained from } 200 \text { participants working in different } \\
\text { sectors by survey method. Factor analysis, reliability, and validity analysis were used to analyze the } \\
\text { obtained data and structural equation modeling was used to test the research hypotheses. }\end{array}$ \\
\hline & $\begin{array}{l}\text { Findings - The results indicate that work cognition inventory has a positive effect on work-related } \\
\text { flow experience and insider status, and perceived insider status has no effect on work-related flow } \\
\text { experience. }\end{array}$ \\
\hline & $\begin{array}{l}\text { Discussion - In line with the findings of the research, it was observed that differentiating the } \\
\text { working environment offered by the organizations to the employees and providing a unique } \\
\text { working experience may provide advantages to organizations. In addition, a holistic assessment of } \\
\text { organizational, interpersonal and job experience will positively affect the insider status and flow } \\
\text { experience of employees. }\end{array}$ \\
\hline
\end{tabular}

\section{Önerilen Atıf/Suggested Citation}

Müceldili., B., Tatar., B., Erdil., O. (2019) Çalışanlarda Akış Deneyimi Oluşturulması: İş Biliş Envanteri ve İçsel Statünün Önemi Açısından Bir İnceleme, İşletme Araştırmaları Dergisi, 11 (4), 2845-2855. 


\section{GİRIŞ}

Akış deneyimi bireylerin davranışları üzerinde yarattığı olumlu etkiler sebebiyle psikoloji (Csikszentmihalyi, 1990), pazarlama (Donna ve Novak, 1997), spor (Catley ve Duda, 1997), eğitim ( (Shernoff vd., 2003) gibi farklı alanlardaki araştırmacıların ilgisini çekmiştir (Demerouti, 2006). Örgütsel psikoloji perspektifinden ele alındığında, çalışanların günlük hayatlarına nazaran iş yaşamlarında daha fazla akış deneyimi yaşamaları ve akış deneyimi yaşadıkları durumlarda daha pozitif deneyimlere sahip olmaları (Csikszentmihalyi, 1990), araştırmacıları özellikle örgütsel bağlamda akış deneyimini incelemeye yöneltmiştir. Benzer şekilde akış deneyimi, psikolojik iyi oluş (Rivkin vd., 2018), yaratıcılık (Zubair ve Kamal, 2015; Bakker, 2005), performans (Demerouti, 2006; Bakker, 2008) ve iş tatmini (Bakker, 2008) gibi çalışan davranışları üzerindeki olumlu etkileri sebebiyle kapsamlı olarak incelenmesi ve değerlendirilmesi gereken bir kavramdır. Bu bağlamda akış deneyiminin yaşanmasında belirleyici olan unsurların incelenmesinin çalışan tutum ve davranışlarını anlamada faydalı olacağı düşünülmüştür. İş yaşamında akış deneyimini inceleyen çalışmalar da bu bakış açısıyla akış deneyiminin yaşanmasına olanak sağlayacak öncüllerin neler olabileceğine odaklanmıştır (Smith vd., 2012).

Bu bağlamda İş Gereklilikleri-Kaynakları (İGK) Modeli çerçevesinde, çalışanların özellikle kendilerinden beklenen iş taleplerinin, sahip oldukları profesyonel yeteneklerle uyumlu ve orantılı olduğu durumda akış deneyimi yaşadıkları belirlenmiştir (Bakker, 2008). Öte yandan çalışanlara sağlanan örgütsel kaynaklar da çalışanlarda kendilerinden beklenen talepleri karşılayabilecekleri inancını yaratmakta (Bakker, Demerouti ve Euwema, 2005) ve motivasyonlarını artırmaktadır. Sağlanan iş kaynakları; verilen görevlerin başarılı bir şekilde yerine getirilmesini ve çalışanların kişisel gelişimlerine katkı sağlayabilecek fiziksel, psikolojik, sosyal ya da örgütsel unsurları içermektedir (Bakker ve Demerouti, 2007). Çalışanlara performansları ile ilgili verilen geribildirimler, kişisel gelişimleri için sağlanan olanaklar, çalışma arkadaşları ya da yöneticilerinden gördükleri destek iş kaynaklarına örnek teşkil etmektedir. Sağlanan bu kaynaklar çalışanların gelişimine sağladığı katkı sebebiyle içsel bir motivasyon yaratırken, iş hedeflerinin başarıyla tamamlanmasını sağlaması sebebiyle dışsal bir motivasyon sağlamakta (Bakker ve Demerouti, 2007) ve akış deneyimi yaşamalarında etkili olmaktadır (Mäkikangas vd., 2010).

Bu bulgulardan yola çıarak bu çalışma kapsamında iş akış deneyimi için önemli bir öncül olabileceği düşünülen ve İş Gereklilikleri-Kaynakları (İGK) Modeli kapsamında ele alınan iş kaynaklarının örgütsel, sosyal ve işle ilgili unsurları içerisinde barındırması sebebiyle İş Biliş Envanteri üzerinde durulmuştur. İş Biliş̧ Envanteri, çalışanların içerisindeki bulundukları kurumda örgütsel, iş ve kişiler arası ilişkiler bağlamında yaşadıkları deneyimlere ilişkin bilişsel değerlendirmelerini belirlemeye yönelik bir araçtır. Envanter içerisindeki deneyim unsurlarının, iş kaynakları benzeri bir etki yaratma potansiyeli ve çalışanların niyetleri ve davranışları üzerindeki olumlu etkileri göz önünde bulundurulduğunda, çalışanların akış deneyimi yaşamasında ve kendilerini kurumlarının bir parçası olarak hissetmelerinde etkili olacağı beklenmektedir. Buna ek olarak İş Biliş Envanteri içerisindeki deneyim unsurlarının, temelde çalışanların kendilerini kurumları için değerli ve önemli hissetmelerine dayanan içsel statü üzerindeki etkileri ve içsel statünün akış deneyimiyle olan ilişkisi incelenmiştir.

\section{KAVRAMSAL ÇERÇEVE}

\subsection{Işs Biliş Envanteri}

Çalışanlar, üyesi oldukları kurumun ve yaptıkları işlerin özeliklerini, kurum içerisinde yaşadıkları deneyimleri önemsemekte ve bu bağlamda değerlendirmelerde bulunmaktadır. Çalışanların iş ortamındaki niyetleri ve iyi oluş düzeyleri üzerinde önemli etkilere sahip olması ve nihayetinde çalışan davranışlarında belirleyici olması sebebiyle çalışanların kurumlarına ilişkin bu değerlendirmelerinde belirleyici olan unsurların incelenmesi önem taşımaktadır (Zigarmi vd., 2011).

Bu bağlamda, çalışanların sahip oldukları değer ve inançlar gibi kişisel özellikleri ile çalışanların kurumları hakkında ne düşündükleri (bilişsel faktörler) ve ne hissettiklerinin (duygusal faktörler), değerlendirme sürecinde belirleyici olduğu belirtilmiştir (Zigarmi vd., 2009). Bunun yanı sıra Zigarmi ve diğerleri (2009), çalışanların işleri ve kurumlarına yönelik olarak yaptıkları değerlendirmelerinin önemli bir ayağı olan kurum içerisinde politika, prosedürler ve iş koşullarına dair bilişsel algıları belirlemeye yönelik bir ölçüm aracının gerekliliğine işaret etmiştir. Bu amaçla Nimon ve diğerleri (2011) çalışanların iş ortamı ve bu ortam içerisindeki bilişsel değerlendirmelerini temel alan İş Biliş Envanterini geliştirmiştir. İş biliş envanteri, çalışanların işe karşı 
tutkunluklarının oluşumunda belirleyici olan iş deneyimleri esas alınarak hazırlanmış olup, bu unsurlar iş deneyimi, örgütsel deneyim ve kişiler arası deneyim boyutları bağlamında değerlendirilmiştir (Nimon vd., 2011).

İş deneyimi; otonomi, anlamlı iş, görev çeşitliliği ve iş yükü dengesi boyutlarından oluşmaktadır. Otonomi kavramı çalışanların görev ve sorumlulukları gerçekleştirirken yetkiye sahip olma düzeylerini ve işleriyle ilgili karar verme özgürlüklerini ifade etmektedir. Anlamlı iş, çalışanların yaptıkları işleri kurum içindeki ve dışındaki bireyler için ne derece önemli olduğu bağlamında şekillenmektedir (Nimon ve Zigarmi, 2015)

Kişiler arası deneyim; işbirliği, lider ile bağlantı, iş arkadaşları ile bağlantı ve geribildirim boyutlarından oluşmaktadır. Işbirliği, kurum içerisindeki birim içi ve birimler arasındaki faaliyetlerde rekabetten işbirliğinin hâkim olması, kurumsal hedeflerin gerçekleşmesi için kaynakların ve bilgilerin paylaşılmasına, işlerin dayanışma içerisinde gerçekleştirilmesine dayanmaktadır. Lider ile bağlantı çalışanlar ile yöneticileri arasında sürekli ve karşılıklı iletişimi, yöneticilerin çalışanların istek ve ihtiyaçlarını önemseyerek onları her durumda desteklemeleri nispetinde şekillenmektedir. Benzer şekilde iş arkadaşları ile bağlantı kavramı da çalışanların, çalışma arkadaşları ile olan ilişkilerin gücü ve destekleyici bir çalışma ortamının varlığı ile orantılıdır. Geribildirim, çalışanların performanslarına dair aldıkları bilgileri, bu bilgilerin doğruluk derecesi ve adil olma durumuyla ilgili algılarını ifade etmektedir (Nimon vd., 2011).

Örgütsel deneyim ise dağıtımsal adalet, prosedürel adalet, gelişim ve performans beklentileri boyutlarından oluşmaktadır. Dağıtımsal adalet çalışanların kurumlarına sağladıkları katkı ve ürettikleri girdi ile aldıkları çıktıları, diğer çalışanların girdi ve çıktılarıyla kıyaslaması sonucu eşitlik ve adaletin gözetilmesi durumuna karşı algılarını ifade etmektedir. Gelişim, kurumun çalışanların bireysel ve kariyer gelişimine yönelik eğitim faaliyetlerini ve sürekli öğrenmeye yönelik gösterdikleri destekleyici faaliyetlerini kapsamaktadır (Nimon ve Zigarmi, 2015).

Çalışanlar, bu üç temel deneyim ve unsurları ışığında, iş yaşamları ve kurumlarına dair bilişsel değerlendirmelerini kendi beklentileriyle klyaslayarak olumlu ya da olumsuz bir duygu geliştirmektedir (Shuck vd., 2018). Bu noktada yapılan bu bilişsel değerlendirmeler, aynı zamanda çalışanların iyi oluş düzeylerini etkilemekte ve nihayetinde yüksek performans gösterme, kurumu onaylama, ihtiyari çaba gösterme, örgütsel vatandaşlık davranışı gösterme ve işte kalma niyeti üzerinde etkili olmaktadır (ThibaultLandry, 2018).

Tüm bu hususlar göz önünde bulundurulduğunda, kurumların çalışanların bilişsel değerlendirmeleri, duyguları, iyi oluş ve niyetleri arasındaki bağlantıları anlayarak, iş ve örgütsel ortamları bu bağlamda dizayn etmeleri ya da düzenlemeleri gerektiği görülmektedir (Nimon vd., 2011).

\section{HİPOTEZ GELISTTİRME}

\section{1. İş Biliş Envanteri ve İçsel Statü}

Organizasyonlar ve çalışanlar arasındaki ilişkiler çok sayıda çalışmaya konu olmuş ve temelde Sosyal Mübadele teorisi ve Teşvik-Katkı Modeli çerçevesinde incelenmiştir. Sosyal mübadele teorisi bağlamında değerlendirildiğinde çalışanlar ile organizasyon arasındaki ilişkilerde karşılıklılık esasının hâkim olduğu görülmektedir (Blau, 1964). Bu ilişki içerisinde organizasyonlar çeşitli yollarla çalışanlarına yatırım yapmakta ve çalışanların da bunun karşılığında performans gibi beklentileri karşılama eğiliminde olacağı öngörülmektedir.

İçsel statü, organizasyon ve çalışan ilişkisinde farklı bir boyuta odaklanmakta ve çalışanların kendilerini ne derece kurumun bir parçası olarak hissettiğini, bağlı oldukları kuruma karşı hissettikleri aidiyeti ifade etmektedir (Stamper ve Masterson, 2002). Bu açıdan değerlendirildiğinde, çalışanların kendilerini içsel statüde hissetmesi elbette ki kendisine sağlanan örgütsel yatırımlar ve desteklerle orantılı şekilde gelişecektir (Stamper ve Masterson, 2002). Bir başka deyişle, organizasyonlar tarafından sağlanan eğitim imkânları, terfiler ve kariyer gelişim programları gibi faydalar, çalışanların kendilerini kurumları için değerli hissetmelerini, yüksek aidiyet algısı geliştirmelerine ve kendilerini örgütün bir parçası olarak görmelerini sağlamaktadır. Masterson ve Stamper (2003) tarafından geliştirilen algılanan örgütsel üyelik kavramına göre ise çalışanlar, kurumları tarafından ihtiyaçları karşılandığı durumlarda daha fazla motive olmakta ve kendilerini kurumlarının bir üyesi olarak hissetmektedir. Bu ihtiyaçlar ekonomik ihtiyaçlar (maaş ve yan haklar), gelişim ihtiyacı (gelişim fırsatları, eğitimler, yenilikçi görev ve sorumluluklar ve bu sorumlulukları yerine getirmede 
yetkilendirmenin yapılması) ve ilişki ihtiyacı (çalışma arkadaşları ve yöneticilerle güçlü ilişkiler) şeklinde sinıflandırılmıştır.

Sınıflandırılan bu ihtiyaçların, İş Biliş Envanterinde çalışanların kurumlarına ilişkin bilişsel yargı ve değerlendirmelerinde temel aldıkları örgütsel deneyim (gelişim ihtiyaçları), iş deneyimi (ekonomik ve gelişim ihtiyaçları) ve kişiler arası deneyime (ilişkisel ihtiyaçlar) karşılık geldiği görülmektedir. Bu bilgiler ışığında kapsadığı unsurlar itibariyle İş Biliş Envanterinin, çalışanların kendilerini kurumlarının üyesi ve bir parçası olarak hissetmelerine katkı sağlayacağı görülmektedir. Öte yandan çalışanların kurum içerisinde karar alma süreçlerine katılımının teşvik edilmesinin, çalışanlarda kendilerine değer verildiği algısının bir sonucu olarak kurumlarını daha çok sahiplendiklerini ve kendilerini içsel statüde hissetmelerini sağladığı ortaya konulmuştur (Ding ve Shen, 2017:414). Benzer şekilde yöneticilerinden destek gören ve önemsendiğini hisseden, bunun yanı sıra kurum içerisindeki karar alma süreçlerine katılımı desteklenen çalışanların da aidiyet duygularının yüksek olduğu görülmüştür (Hui, Lee ve Wang, 2015). Çalışanların yetkilendirilmesi de çalışanların kuruma dâhil edildiklerini, kurumları tarafından kabul gördüklerini ve kurumun içerisinde bir statüde konumlandığını işaret etmektedir (Chen ve Aryee, 2007).

Teşvik-Katkı Modeli (March ve Simon, 1958) de benzer şekilde kurum tarafından sağlanan teşvikleri ekonomik teşvikler, gelişim teşvikleri (eğitim fırsatları ve kararlara katılım) ve sosyal desteğe yönelik teşvikler (algılanan yönetici ve çalışma arkadaşları desteği) olmak üzere üç grupta sınıflandırmıştır (Dai ve Chen, 2015). $\mathrm{Bu}$ teşviklerden yararlanan çalışanların kurum için değerli olduklarını hissedecekleri, daha yüksek aidiyet duygusu taşıyacakları ve içsel statü algılarının yüksek olacağı belirtilmiştir ( Stamper ve Masterson, 2002). Bu bilgiler ışığında:

$\mathrm{H}_{1}$ İş biliş envanteri, içsel statü üzerinde pozitif bir etkiye sahiptir.

\section{2. İçsel Statü ve İş Akış Deneyimi}

İşa akış deneyimi “işe dalma, işi sevme ve içsel motivasyon ile nitelendirilen çalışanların işlerinde yaşadığı kısa süreli yoğun deneyim" olarak ifade edilmiştir (Bakker, 2005). Tanım içerisinde yer alan dalma kavramı, çalışanların tamamen işlerine konsantre olması ve zamanın nasıl geçtiğini anlamama durumudur. İşi sevme, çalışanın iş hayatında kendini mutlu hissetmesi ve iş ortamına dair olumlu yargı ve düşüncelere sahip olmasıdır. Son olarak içe dönük çalışma motivasyonu ise çalışanların herhangi bir zorunluluk olmaksızın, içsel olarak işleriyle ilgilenmeleri ve bu durumdan tatmin olmalarını ifade etmektedir (Bakker, 2008).

Çalışanlar özellikle yetenekleri ve sorumlu oldukları görevler arasında bir dengenin söz konusu olması durumunda akış deneyimi yaşamaktadır (Bakker, 2008). Alan yazında yer alan çalışmalar incelendiğinde çalışanların kurumlarına duyduğu bağlılık (Rivkin vd., 2018), psikolojik sermaye düzeylerinin (Zubair, 2015) akış deneyimleri üzerinde etkili olduğu görülmektedir. Öte yandan Fan (2013) hizmet sektöründeki çalışanlar üzerine yaptığı araştırmada, çalışanların kurumlarına karşı sahip oldukları aidiyet hissinin, akış deneyimi yaşamalarında etkili olduğunu bulgulamıştır. Bu doğrultuda çalışanlar tarafından hissedilen içsel statünün akış deneyimini etkileyeceği beklenmektedir.

$\mathrm{H}_{2}$ : İçsel statü, iş akış deneyimi üzerinde pozitif bir etkiye sahiptir.

\section{3. İş Biliş Envanteri ve İş Akış Deneyimi}

Örgütsel deneyim unsurları açısından değerlendirildiğinde, öğrenme değeri yüksek olan kurumların üyesi olan çalışanlar, iş akış deneyimini daha fazla yaşamaktadır (Van der Heijden ve Bakker, 2011). Çalışanların profesyonel gelişimlerine katkıda bulunan kurumlarda çalışmak, çalışanlarda akış deneyimini meydana getirmektedir (Xanthopouloua vd., 2009).

Örgütsel deneyim ise dağıtımsal adalet, prosedürel adalet, gelişim ve performans beklentileri boyutlarından oluşmaktadır. Dağıtımsal adalet çalışanların kurumlarına sağladıkları katkı ve ürettikleri girdi ile aldıkları çıktıları, diğer çalışanların girdi ve çıtılarıyla kıyaslaması sonucu eşitlik ve adaletin gözetilmesi durumuna karşı algılarını ifade etmektedir. Gelişim, kurumun çalışanların bireysel ve kariyer gelişimine yönelik eğitim faaliyetlerini ve sürekli öğrenmeye yönelik gösterdikleri destekleyici faaliyetlerini kapsamaktadır (Nimon ve Zigarmi, 2015). 
Kişiler arası deneyim boyutları açısından değerlendirildiğinde; liderleriyle yüksek kaliteli ilişkilere sahip olan ve liderleri tarafından destek gören çalışanların akış deneyimi yaşamaları kolaylaşmaktadır (Lan vd., 2017). İ̧̧ arkadaşlarından destek gören ve iyi ilişkiler deneyimleyen çalışanlar işlerini severek yapmakta ve içsel motivasyonları yüksek olmaktadır (Peters vd, 2014). Benzer şekilde çalışanların sosyal anlamda gördükleri destek, akış deneyimlerini olumlu etkilemektedir (Bakker, 2008).

Son olarak iş deneyimi perspektifinden değerlendirildiğinde, çalışanlara işleriyle ilgili karar alabilmeye yönelik yetkilendirmenin yapılması ve otonominin varlığı akış deneyiminin önemli bir belirleyicisidir (Peters vd, 2014; Bakker, 2008). Yapılan işin ve verilen görevlerin anlamlı ve önemli olması, çalışanların yetenekleriyle orantılı olarak çeşitlilik göstermesi çalışanların akış deneyimi yaşamasını mümkün kılmaktadır (Bucher ve Fieseler, 2017).

$\mathrm{H}_{3}$ : İş biliş envanteri, iş akış deneyimi üzerinde pozitif bir etkiye sahiptir.

\section{YÖNTEM}

Çalışma kapsamında öne sürülen araştırma modelinin test edilmesi için 200 katılımcıdan elde edilen veriler üzerinde geçerlilik ve güvenilirlik analizi yapılmıştır. Yapı geçerliliğini test etmek için doğrulayıcı faktör analizi yapılmıştır. Araştırma kapsamında öne sürülen hipotezlerin test edilmesinde yapısal eşitlik modellemesinden yararlanılmıştır.

\subsection{Araştırma Modeli}

$\mathrm{Bu}$ araştırma kapsamında; iş biliş envanteri, içsel statü ve iş akış deneyimi arasındaki ilişkiler incelenmiştir. Bu bağlamda öne sürülen araştırma modeli aşă̆ıda yer almaktadır:

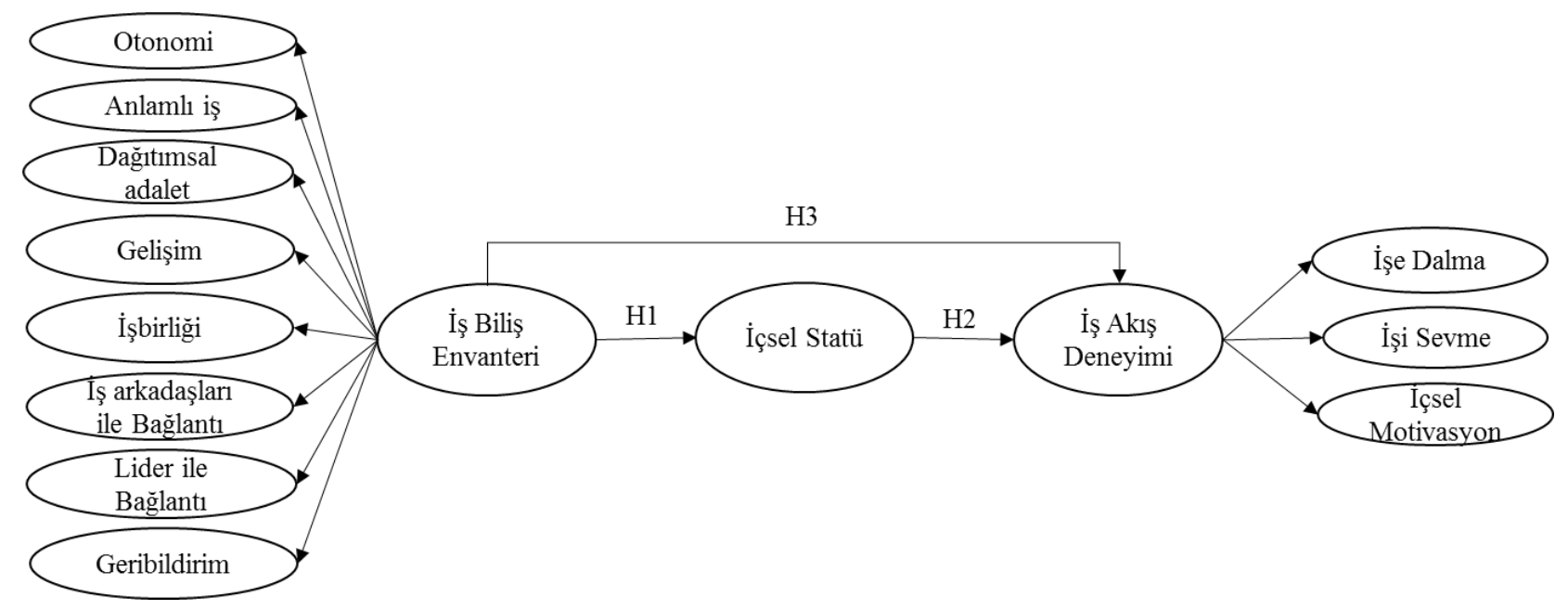

Şekil 1. Araştırma Modeli

\section{2. Örneklem}

Çalışanların iş biliş envanteri kapsamında sahip oldukları deneyimlerin, içsel statüleri ve akış deneyimi üzerindeki etkilerinin belirlemek amacıyla, Gerekli verileri toplamak için kolayda örnekleme yönteminden yararlanılmıştır. Bu bağlamda şu anda aktif olarak çalışma hayatı devam eden yüksek lisans ve doktora öğrencileri anahtar bilgi verici (key informant) olarak belirlenmiştir. Öğrencilerle yüz yüze anket çalışması yapılmış, ankette soruların doğru veya yanlış cevap olmadığı ve verdikleri bilgilerin gizli tutularak sadece bilimsel bir çalışma için kullanılacağı bilgisi verilmiştir. Ardından bu öğrencilere kendi işyerinde çalışan arkadaşlarına anketi uygulamaları söylenmiştir. Her öğrenci, çalıştıkları kurumda görev yapan arkadaşlarından 2 veya 3 anketi yüz yüze yaparak toplamıştır. Böylece farklı sektörlerden katılımcılara ulaşma imkânı doğmuştur. Toplanan anketler incelendikten sonra, bazı anketlerin tam doldurulmadığı görülmüş ve o anketler çalışmadan çıkarılmıştır. Nihayetinde, çalışmada 200 beyaz yakalı çalışandan veri toplanmıştır.

Yapısal eşitlik modellemesinde, araştırma modelinin çok karmaşık olmadığı ve verinin normal dağılım gösterdiği çalışmalarda örneklem büyüklüğü olarak, 200 katılımcı standart örneklem büyüklüğü olarak belirlenmiştir (Kline, 2005). Benzer şekilde veri setinde normalliğin korunması için örneklem düzeyinin minimum 200 katılımcı olması gerektiği belirtilmiştir (Hair vd., 2010). Öte yandan, araştırmalar için madde 
sayısının beş katı bir örneklem büyüklügünün yeterli olacağı belirtilmiştir (Streiner, 1994; Child, 2006). Çalışma kapsamında 43 sorudan oluşan bir anket kullanıldığ göz önünde bulundurulduğunda örneklem büyüklügünün 215 olması gerekmekte ve çalışma kapsamında elde edilen örneklem büyüklüğünün bu rakama oldukça yakın olduğu görülmektedir. Bu değerlendirmeler ışığında bu çalışma için örneklem büyüklüğü olarak 200 katılımcı ile analizler yapılmaya başlanmıştır.

Örneklem profili açısından değerlendirildiğinde ise; araştırmaya katılan katılımcıların \%54,5'i kadın; \%5,5'i 18-24, \%64,8'i 25-34, \%24,2'si 35-44, \%4,4'ü 45-54, \%1,1'i 55 ve üzeri yaş aralığındadır. Katılımcıların \%1,5' ön lisans, \%58,5'i lisans, \%36,5'i yüksek lisans ve \%3,5'i doktora mezunudur. Deneyim süreleri açısından değerlendirildiğinde, katılımcıların \%8,5'i 1 yıldan az, \%45'i 1-5 yıl arası, \%25'i 6-10 yıl arası ve \%21,5'i 11 yıl ve üzeri iş deneyimine sahiptir. Buna ek olarak katılımcların \%17,5'i imalat, \%16's1 eğitim, \%6'sı sağlık, \%6's1 bankacılık ve finans, \%4'ü inşaat, \%2,5'i turizm, \%0,5'i bilgi teknolojileri, \%39,5'i ise kimya, ulaştırma, perakende vb. sektörlerde çalışmaktadır.

\subsection{Veri Toplama Araçlan}

Araştırma kapsamında elde edilen veriler anket yöntemi ile toplanmıştır. Anket formu 3 bölümden oluşmaktadır. Birinci bölümde katılımcıların demografik özelliklerini belirlemek amacıyla 7 soru yer almaktadır. İkinci bölümde iş biliş envanteri, üçüncü bölümde ise çalışanların içsel statü ve iş akış deneyimlerine yönelik ifadelere yer verilmiştir.

İş Biliş Envanteri: Nimon ve Zigarmi (2015) tarafından geliştirilen 24 soruluk İş Biliş Envanteri aracılığıyla ölçümlenmiştir. Ölçek iş deneyimi, örgütsel deneyim ve kişiler arası deneyim kapsamında ele alınan 8 boyuttan oluşmaktadır.

İçsel Statü: Katılımcıların içsel statülerine ilişkin algı düzeylerini ölçmek için Stamper ve Masterson (2002) tarafından geliştirilen 6 soruluk Algılanan İçsel Statü Ölçeğinden faydalanılmıştır.

İş akış deneyimi: Çalışanların akış deneyimlerini ölçmek için Bakker (2008) tarafından geliştirilen, üç boyut (işe dalma, işi sevme ve içsel motivasyon) ve 13 sorudan oluşan WOLF (The Work Related Flow Inventory) Ölçeğinden yararlanılmıştır. Tüm ölçekler 5`li Likert ölçeği kullanılarak ölçümlenmiştir.

\section{BULGULAR}

Araştırmada kullanılan ölçeklerin yapı geçerliliğini test etmek amacıyla doğrulayıcı faktör analizi yapılmıştır. Kriter değerin altında kalan 7 maddenin analizden çıkarılmasının sonucunda ölçüm modelinin veri ile iyi uyum gösterdiği belirlenmiştir $\left(\chi^{2}(309)=652.652, \mathrm{CFI}=0.92, \mathrm{TLI}=0.91, \mathrm{IFI}=.92, \mathrm{PNFI}=.75\right.$ RMSEA $=0.06$, $\left.\chi^{2} / \mathrm{df}=2.112\right)$.

Tablo 1. Faktör analizi ve Güvenilirlik Analizi Sonuçları

\begin{tabular}{lcccc}
\hline Değişken & $\begin{array}{c}\text { Standart Faktör } \\
\text { Yükleri }\end{array}$ & CR & AVE & Cronbach's Alpha \\
\hline İş Biliş Envanteri & & 0.92 & 0.61 & 0.94 \\
Otonomi & 0.742 & 0.77 & 0.62 & 0.76 \\
AUT2 & 0.832 & & & \\
AUT3 & & 0.78 & 0.63 & 0.77 \\
Anlamlı İş & 0.803 & & & \\
MW1 & 0.788 & & & \\
MW2 & & & & \\
Dağ1tımsal Adalet & 0.807 & 0.85 & 0.65 & \\
DJ3 & 0.902 & & & \\
DJ2 & 0.701 & & & \\
DJ1 & & & & \\
Gelişim & 0.821 & 0.85 & 0.66 & \\
GR2 & 0.811 & & & 0.85 \\
GR1 & 0.807 & & & \\
GR3 & & 0.83 & 0.71 & \\
İşirliği & & &
\end{tabular}


B. Müceldili - B. Tatar - O. Erdil 11/4 (2019) 2845-2855

$\mathrm{CO} 2$

$\mathrm{CO} 1$

İş Arkadaşları ile Bağlantı

CC2

CC1

Lider ile Bağlantı

CL3

CL2

CL1

Geribildirim

FB3

FB2

FB1

İçsellik statüsü

PIS1

PIS2

PIS3

PIS4

PIS6

İş Akış Deneyimi

İşe Dalma

ABS1

ABS2

ABS3

ABS4

İşi Sevme

WE2

WE4

WE1

İçsel Motivasyon

INT2

INT3

INT4

INT5
0.938

0.735

0.892

0.745

0.695

0.901

0.787

$0.87 \quad 0.68$

0.87

0.843

0.837

0.799

$0.94 \quad 0.76$

0.93

0.882

0.895

0.859

0.887

0.825

$0.91 \quad 0.76$

0.93

$0.89 \quad 0.67$

0.89

0.801

0.860

0.820

0.800

$0.87 \quad 0.70$

0.87

0.832

0.850

0.820

0.86

0.61

0.86

0.723

0.864

0.806

0.725

Uyum indeksleri: $C F I=0.912, I F I=0.91, T L I=0.90, \chi^{2} / d f=1.795, R M S E A=0.063$

Geçerlilik analizinde uyuşma ve ayrışma geçerliliği test edilmiştir. Bu bağlamda faktör yüklerinin $0.695-0.938$ arasında olduğu ve kriter değerin üzerinde olduğu saptanmıştır (Hair vd., 2010). Elde edilen bulgular uyuşma geçerliliğini doğrulamıştır. Ayrışma geçerliliğ̆i açısından değerlendirildiğinde; ortalama varyans değerlerinin (AVE) karekökünün yapılar arası korelasyon değerinden büyük olduğu ve ayrışma geçerliliği için gerekli olan koşulu sağladığı görülmüştür (Bagozzi and Yi, 1988; Fornell and Larcker, 1981).

Güvenilirlik analizi kapsamında Cronbach's Alpha ve bileşik güvenirlik değerleri incelenmiştir. Sonuç olarak Cronbach's Alpha değerlerinin 0.70'in üzerinde olduğu (Nunnally, 1978) ve bileşik güvenirlik değerlerinin 0.77-0.94 aralığında olduğu ve kriter değer olan 0.60'ın üzerinde olduğu belirlenmiştir (Fornell and Larcker, 1981).

Tablo 2. Tanımlayıcı İstatistikler ve Korelasyon analizi sonuçları

\begin{tabular}{llllll}
\hline & Ort. & St. Sapma & $\mathbf{1}$ & $\mathbf{2}$ & $\mathbf{3}$ \\
\hline 1- İş Biliş Envanteri & 3.7850 & 0.70399 & $(0.78)$ & & \\
2- İçsellik Statüsü & 3.8560 & 0.95426 & $0.780^{* *}$ & $(0.87)$ & \\
3- İş Akış Deneyimi & 3.6473 & 0.80570 & $0.714^{* *}$ & $0.663^{* *}$ & $(0.87)$ \\
\hline
\end{tabular}

${ }^{* *} \mathrm{p}<0.001$ 
Öte yandan Tablo 2'de 3 değişken arasındaki korelasyonlara ilişkin katsayılar ve tanımlayıcı istatistik sonuçları yer almaktadır. Bu sonuçlara göre iş biliş envanteri, içsellik statüsü ve iş akış deneyimi arasında pozitif bir ilişkinin olduğu görülmektedir.

Tablo 3. Hipotez Testleri

\begin{tabular}{llcll}
\hline Hipotez & $\begin{array}{c}\text { Standart Regresyon } \\
\text { Katsayısı }\end{array}$ & $\mathbf{t}$ & Sonuç \\
\hline H1 & İş Biliş Envanteri $\rightarrow$ İçsel Statü & .84 & $6.191^{* *}$ & Desteklendi \\
H2 & İşsel Statü $\rightarrow$ İş Akş̧ Deneyimi & .15 & 1.351 & Desteklenmedi \\
H3 & İş Biliş Envanteri $\rightarrow$ İş Akış Deneyimi & .70 & $4.65^{* *}$ & Desteklendi \\
\hline
\end{tabular}

${ }^{* *} \mathrm{p}<0.001$

Araştırma hipotezlerinin test edilmesinde yapısal eşitlik modellemesinden faydalanılmıştır. Araştırma bulgularına göre modelin veri ile uyumlu olduğu belirlenmiştir $(\chi 2(579)=1039.189, \mathrm{CFI}=0.91, \mathrm{TLI}=0.90, \mathrm{IFI}=.91$, PNFI $=.75$ RMSEA $=0.06, \chi 2 / \mathrm{df}=1.795$ ).

Hipotezlerin test edilmesi amacıyla gerçekleştirilen yol analizi sonuçları Tablo 3'te gösterilmiştir. Buna göre, iş biliş envanteri ve içsel statü arasında pozitif bir ilişkinin olduğu bulgulanmış ve H1 hipotezi desteklenmiştir ( $\beta=.84, \mathrm{p}<.001)$. H2 hipotezi incelendiğinde, içsellik statüsünün iş akış deneyimi üzerinde bir etkisinin olmadığı görülmüş $(\beta=.15, \mathrm{p}>.05)$ ve $\mathrm{H} 2$ hipotezi desteklenmemiştir. Son olarak iş biliş envanterinin iş akış deneyimini pozitif etkilediği saptanmıştır $(\beta=.70, \mathrm{p}<.01)$. Dolayısıyla H3 desteklenmiştir.

\section{SONUÇ VE TARTIŞMA}

Çalışanlar iş yaşamları boyunca yürüttükleri işler, çalışma arkadaşları ya da yöneticileriyle geliştirdikleri ilişkiler ve örgütsel birtakım yaklaşım ve uygulamalar ile ilgili deneyimler kazanmaktadır. Çalışanların elde ettikleri bu deneyimlerin kalitesine ve eşsizliğine ilişkin bilişsel değerlendirmeleri, onların iyi oluş düzeylerini etkilediği kadar işte kalma, ekstra çaba gösterme, kurumunu destekleme gibi niyetlerini de etkilemekte (Zigarmi vd., 2011) ve pozitif davranışlar göstermelerine katkıda bulunmaktadır. Bu bağlamda, bu çalışma kapsamında, iş biliş envanteri içerisindeki deneyim unsurları ile içsel statü ve iş akış deneyimi gibi pozitif çalışan davranışları arasındaki ilişkiler incelenmiştir.

İlk olarak iş biliş envanteri kapsamındaki iş deneyimlerinin çalışanların içsel statüsü üzerinde pozitif bir etkisi olduğu saptanmıştır. Elde edilen bu bulgu, Teşvik-Katkı Modeli çerçevesinde öne sürülen ve çalışanlara ekonomik, gelişim ve sosyal anlamda sağlanan desteklerin (Dai ve Chen, 2015), onların kurumlarına sağlayacakları katkının yanı sıra aidiyet, sahiplenme ve içsel statü algıları üzerinde etkili olacağı düşüncesini güçlendirmektedir (Stamper ve Masterson, 2002). Elde edilen bu bulguyla paralel olarak Masterson ve Stamper (2003); çalışanların ekonomik, gelişim ve ilişki ihtiyacı giderildiği ölçüde kendilerinin kurumlarının bir parçası olarak göreceğini bulgulamıştır. İş Biliş Envanterinde çalışanların kurumlarına ilişkin bilişsel değerlendirmelerinde esas aldıkları örgütsel deneyimlerin gelişim ihtiyacına; iş deneyimlerinin ekonomik ve gelişim ihtiyaçlarına ve kişiler arası deneyimlerin de ilişkisel ihtiyaçlara karşılık geldiği göz önünde bulundurulduğunda; bu çalışma kapsamında edinilen iş biliş envanteri ve içsel statü arasındaki ilişki, literatürde yer alan araştırma bulgularıyla tutarlıdır.

Benzer şekilde iş biliş envanteri, çalışanların akış deneyimini pozitif etkilemektedir. İş Biliş Envanteri, çalışanların içerisinde bulundukları kurumda örgütsel, iş faaliyetleri ve kişiler arası ilişkiler bağlamında yaşadıkları deneyimlere dayanmakta ve İş Gereklilikleri-Kaynakları (İGK) Modeli kapsamında öne sürülen iş kaynaklarını kapsamaktadır. Bu model kapsamında çalışanlara işlerinde başarılı olmaları için sağlanan fiziksel, psikolojik, sosyal ya da örgütsel kaynakların iyi oluş düzeyleri ve akış deneyimleri üzerinde etkili olduğu belirtilmiştir (Bakker ve Demerouti, 2007; Mäkikangas vd., 2010). Öte yandan çalışanlarının kişisel ve profesyonel gelişimine önem veren ve buna yönelik faaliyetler yürüten kurumlardaki çalışanlar akış deneyimini yaşamaktadır (Van der Heijden ve Bakker, 2011). Bunun yanı sıra çalışanlar açısından kurum içerisinde gerek yöneticilerinden (Lan vd., 2017), gerekse çalışma arkadaşlarından (Peters vd, 2014) destek görmek ve iyi ilişkilere sahip olmak, çalışanların akış deneyimini olumlu etkilemektedir. Benzer şekilde çalışanların yaptıkları işte otonomiye sahip olması ve anlamlı bir görev üstleniyor olması da akış deneyimlerini etkilemektedir. Değinilen tüm bu hususlar, iş biliş envanteri kapsamında yer alan işle ilgili 
deneyim, örgütsel deneyim ve kişilerarası deneyime karşıllk gelmekle birlikte, literatürde yer alan bulgularla benzer şekilde iş biliş envanteri ve iş akış deneyimi arasında pozitif bir ilişkinin olduğu saptanmıştır.

Son olarak şaşırtıcı bir şekilde çalışanların içsel statü algılarının iş akış deneyimleri üzerinde bir etkisinin olmadığı belirlenmiştir. Bu çalışmada içsel statü, çalışanların algısı çerçevesinde ölçümlenmiştir. Fakat çalışanların gerçekte kurumun bir parçası olması ya da içsel statüde olmasının, kendi algıladıkları içsellik statü durumundan farklı olması muhtemeldir. Stamper ve Masterson (2002) kurumların içsel statüde olan ve olmayan çalışanlar arasında bir ayrım gözettiğini ve içsel statüde olan çalışanlara eğitim, terfi ya da ekstra yan haklar gibi imkânlar sağladıklarını belirtmiştir. Bu bağlamda, daha subjektif bir ölçüt olan kişisel algılama ve hisler doğrultusunda kendini içsel statüde hisseden fakat kendisine bu ayrıcalıklı imkânların sağlanmadığı ve gerçekte içsel statüde olmayan çalışanların akış deneyimi yaşamaması muhtemeldir. Bu nedenle, içsel statü anlamında çalışanların gerçekte deneyimledikleri durum ile algıları itibariyle kendilerini konumlandırdıkları statü arasında bir denge ve uyumun olması gerekmektedir. Elde edilen bu bulgu, iş akış deneyiminin çalışanların içsellik statüsü ya da aidiyet algıları gibi önemli davranışları üzerindeki etkilerini inceleyen kısıtlı çalışma alanına katkıda bulunmuştur.

Yönetsel açıdan değerlendirildiğinde ise elde edilen bulgular ışığında; örgütsel, kişiler arası ve iş ile ilgili deneyimlerin bütüncül olarak ele alınmasının gerektiği görülmektedir. Öte yandan tüketici perspektifinde önemle üzerinde durulan müşteri deneyiminin yanı sıra, kurum içerisinde iç müşteri durumunda olan çalışanlar için de kurum içerisinde sunulan deneyimin farklılaştırılması ve eşsiz kılınması için faaliyetler geliştirilmesi faydalı olacaktır. Buna ek olarak bu deneyimler ve sunulan çalışma ortamı, çalışan davranışları üzerinde yarattığı olumlu etkileri sebebiyle üzerinde durulması gereken önemli bir husustur. Bu bağlamda bu araştırma kapsamında çalışanların iş deneyimlerine ilişkin bilişsel değerlendirmelerinin içsel statü algıları üzerinde olumlu etki yarattığı görülmüştür. Çalışan devir oranlarının yüksek olduğu ve yetenekli çalışanları kurum içerisinde tutmanın giderek zorlaştığı günümüz iş dünyasında, çalışanların kurumlarına duydukları aidiyet gibi önemli bir duyguyu beraberinde getirmesi sebebiyle çalışan deneyimlerinin iyi bir şekilde yönetilmesi gerekmektedir. Akış deneyimi bağlamında değerlendirildiğinde ise yöneticiler ve kurumlar açısından çalışanların gerçekte ve algısal olarak hissettikleri içsellik statüsünün paralel olması gerektiği saptanmıştır. Bir başka deyişle, algısal olarak kendini içsel statüde hisseden çalışanların, kurum açısından içsel statüde olan çalışanlarla benzer teşviklerden yararlanmaması, her iki durum arasında bir dengesizlik yaratacaktır. Nitekim içsel statü algısı ile akış deneyimi arasında bir ilişki bulunmaması, bu düşünceyi destekler niteliktedir.

Araştırmanın literatüre sağladığı teorik ve pratik katkılarının yanı sıra bazı kısıtları bulunmaktadır. Araştırma kapsamında kolayda örnekleme yöntemi ile Marmara bölgesinde, farklı sektörlerde çalışan 200 beyaz yakalı çalışandan veriler toplanmıştır. Gelecek araştırmalarda örneklemin genişletilmesi bulguların genellenebilirliğine önemli katkılar sağlayacaktır. Araştırmanın kesitsel olması ise bir diğer kısıttır. Belirli bir zaman dilimi yerine belirli aralıklarla yapılan ölçümlerle boylamsal bir araştırma yürütülmesi faydalı olacaktır.

Bu çalışma kapsamında sadece iş biliş envanteri, içsel statü ve iş akış deneyimi arasındaki ilişki incelenmiştir. Gelecek araştırmalarda özellikle kişi-örgüt uyumu gibi değişkenler aracılığıyla deneyim içerisinde yer alan unsurların, çalışanların değer atfettiği faaliyetlerle ne derece uyumlu olduğunun belirlenmesi faydalı olacaktır. Zigarmi ve Roberts (2012) tarafından yürütülen çalışmada çalışanların liderleri ile bağlarının kuvvetli olmasının mevcut kurumlarında kalma ve gönüllü olarak sorumluluklarından daha fazla iş yapma eğiliminde olduğu ifade edilmiştir. Bu bağlamda, farklı liderlik tarzlarına sahip lider ve yöneticilerin, çalışanların bilişsel değerlendirmeleri üzerindeki etkilerinin kapsamlı olarak incelenmesinin faydalı olması beklenmektedir. İş biliş envanteri kapsamında ele alınan deneyim unsurlarının tükenmişlik, işten ayrılma niyeti, sinizm gibi olumsuz çalışan davranışları üzerindeki etkisinin incelenmesi de literatüre katkı sağlayacaktır. Buna ek olarak, çalışanların içsel statü algısının yanı sıra gerçekteki içsel statülerinin de ölçümü ile birlikte elde edilen bulgular literatüre katkı sağlayacaktır. 


\section{KAYNAKÇA}

Bakker, A. B. (2008). The work-related flow inventory: Construction and initial validation of the WOLF. Journal of vocational behavior, 72(3), 400-414.

Bakker, A. B., and Demerouti, E. (2007). The job demands-resources model: State of the art. Journal of managerial psychology, 22(3), 309-328.

Bakker, A. B., Demerouti, E., and Euwema, M. C. (2005). Job resources buffer the impact of job demands on burnout. Journal of Occupational Health Psychology, 10, 170-180.

Bucher, E., and Fieseler, C. (2017). The flow of digital labor. New media \& society, 19(11), 1868-1886.

Catley, D., and Duda, J. L. (1997). Psychological antecedents of the frequency and intensity of flow in golfers. International Journal of Sport Psychology, 28(4), 309-322.

Chen, Z. X., and Aryee, S. (2007). Delegation and employee work outcomes: An examination of the cultural context of mediating processes in China. Academy of Management Journal, 50(1), 226-238.

Child, D. (2006). The essentials of factor analysis (3rd ed.). London, England: Continuum.

Csikszentmihalyi, M. (1990). Flow: The Psychology of Optimal Experience, NewYork: Harper Collins Modern Classics.

Dai, L., and Chen, Y. (2015). A systematic review of perceived insider status. Journal of Human Resource and Sustainability Studies, 3(02), 66.

Demerouti, E. (2006). Job characteristics, flow, and performance: The moderating role of conscientiousness. Journal of Occupational Health Psychology, 11(3), 266.

Ding, C. G., and Shen, C. K. (2017). Perceived organizational support, participation in decision making, and perceived insider status for contract workers: A case study. Management Decision, 55(2), 413-426.

Donna, L., and Novak, H. T. P. (1997). A new marketing paradigm for electronic commerce. The information society, 13(1), 43-54.

Fan, S. T. H. H. L. (2013). The Relationships among Organizational Belonging, Flow Experience, and Positive Behaviors of Employees in a Beauty Salon Organization. Management Review, 32, 131-136.

Hair, J. F., Black, W. C., Babin, B. J., \& Anderson, R. E. (2010). Multivariate data analysis: Global edition. Upper Saddle River, NJ: Prentice Hall.

Hui, C., Lee, C., and Wang, H. (2015). Organizational inducements and employee citizenship behavior: The mediating role of perceived insider status and the moderating role of collectivism. Human Resource Management, 54(3), 439-456.

Kline R (2005)Principles and Practice ofStructural Equation Modeling, 2nd ed. The Guilford Press, London.

Lan, J., Wong, C. S., Jiang, C., and Mao, Y. (2017). The effect of leadership on work-related flow: a moderated mediation model. Leadership \& Organization Development Journal, 38(2), 210-228.

Mäkikangas, A., Bakker, A. B., Aunola, K., and Demerouti, E. (2010). Job resources and flow at work: Modelling the relationship via latent growth curve and mixture model methodology. Journal of Occupational and Organizational Psychology, 83(3), 795-814.

Masterson, S. S., and Stamper, C. L. (2003). Perceived organizational membership: An aggregate framework representing the employee-organization relationship. Journal of Organizational Behavior: The International Journal of Industrial, Occupational and Organizational Psychology and Behavior, 24(5), 473-490.

Nimon, K., Zigarmi, D., Houson, D., Witt, D., and Diehl, J. (2011). The work cognition inventory: Initial evidence of construct validity. Human Resource Development Quarterly, 22(1), 7-35.

Perrewé, P. L., Hochwarter, W. A., Ferris, G. R., McAllister, C. P., and Harris, J. N. (2014). Developing a passion for work passion: Future directions on an emerging construct. Journal of Organizational Behavior, 35(1), 145-150. 
B. Müceldili - B. Tatar - O. Erdil 11/4 (2019) 2845-2855

Peters, P., Poutsma, E., Van der Heijden, B. I., Bakker, A. B., and Bruijn, T. D. (2014). Enjoying new ways to work: An HRM-process approach to study flow. Human resource management, 53(2), 271-290.

Rivkin, W., Diestel, S., and Schmidt, K. H. (2018). Which daily experiences can foster well-being at work? A diary study on the interplay between flow experiences, affective commitment, and self-control demands. Journal of Occupational Health Psychology, 23(1), 1-13.

Shernoff, D. J., Csikszentmihalyi, M., Schneider, B., and Shernoff, E. S. (2014). Student engagement in high school classrooms from the perspective of flow theory. School Psychology Quarterly, 18(2), 158-176.

Shuck, B., Peyton Roberts, T., and Zigarmi, D. (2018). Employee Perceptions of the Work Environment, Motivational Outlooks, and Employee Work Intentions: An HR Practitioner's Dream or Nightmare?. Advances in Developing Human Resources, 20(2), 197-213.

Smith, M. B., Koppes Bryan, L., and Vodanovich, S. J. (2012). The counter-intuitive effects of flow on positive leadership and employee attitudes: Incorporating positive psychology into the management of organizations. The Psychologist-Manager Journal, 15(3), 174-198.

Stamper, C. L., and Masterson, S. S. (2002). Insider or outsider? How employee perceptions of insider status affect their work behavior. Journal of Organizational Behavior: The International Journal of Industrial, Occupational and Organizational Psychology and Behavior, 23(8), 875-894.

Streiner, D. L. (1994). Figuring Out Factors: The Use and Misuse of Factor Analysis. The Canadian Journal of Psychiatry, 39(3), 135-140.

Thibault-Landry, A., Egan, R., Crevier-Braud, L., Manganelli, L., and Forest, J. (2018). An empirical investigation of the employee work passion appraisal model using self-determination theory. Advances in Developing Human Resources, 20(2), 148-168.

Van der Heijden, B. I., and Bakker, A. B. (2011). Toward a mediation model of employability enhancement: A study of employee-supervisor pairs in the building sector. The Career Development Quarterly, 59(3), 232248.

Xanthopoulou, D., Bakker, A. B., Demerouti, E., \& Schaufeli, W. B. (2009). Reciprocal relationships between job resources, personal resources, and work engagement. Journal of Vocational behavior, 74(3), 235-244.

Zigarmi, D., Nimon, K., Houson, D., Witt, D., and Diehl, J. (2011). A preliminary field test of an employee work passion model. Human Resource Development Quarterly, 22(2), 195-221.

Zigarmi, D., Nimon, K., Houson, D., Witt, D., and Diehl, J. (2009). Beyond engagement: Toward a framework and operational definition for employee work passion. Human Resource Development Review, 8(3), 300326.

Zubair, A. (2015). Authentic leadership and creativity: Mediating role of work-related flow and psychological capital. Journal of Behavioural Sciences, 25(1), 150-171. 